\title{
High Seroprevalence of Helicobacter Pylori Infection in Inmates: A Case Control Study in a Northern Mexican City
}

\author{
Cosme Alvarado-Esquivel ${ }^{\mathrm{a}, \mathrm{d}}$, Jesus Hernandez-Tinoco ${ }^{\mathrm{b}}$, Luis Francisco Sanchez-Anguiano ${ }^{\mathrm{b}}$, \\ Agar Ramos-Nevarez ${ }^{c}$, Sandra Margarita Cerrillo-Soto ${ }^{c}$, Leandro Saenz-Soto ${ }^{c}$
}

\begin{abstract}
Background: The epidemiology of Helicobacter pylori infection in inmates has not been previously studied. Therefore, we determine the seroepidemiology of $H$. pylori infection in inmates.

Methods: Through a case-control study, inmates from a state correctional facility in Durango, Mexico and subjects without incarceration of the same city were examined for the presence of anti- $H$. pylori IgG antibodies using enzyme-linked immunoassays. Seroprevalence association with socio-demographic, incarceration, clinical and behavioral characteristics of the inmates was also investigated.
\end{abstract}

Results: Antibodies to H. pylori were found in $140(83.3 \%)$ of 168 inmates and in $101(60.1 \%)$ of 168 controls. Seroprevalence of antiH. pylori IgG antibodies was significantly higher in inmates than in controls $(\mathrm{OR}=3.32 ; 95 \% \mathrm{CI}: 1.93-5.71 ; \mathrm{P}=0.000002)$. The seroprevalence of $H$. pylori infection was not influenced by gender, age, or socioeconomic status of inmates. Seropositivity to H. pylori was found in 3 of 3 inmates with peptic ulcer and in 1 of 2 inmates with gastritis. The seroprevalence of $H$. pylori exposure was high regardless the jail section, duration (years) in incarceration and number of incarcerations. Multivariate analysis revealed that $H$. $p y$ lori exposure was positively associated with having tattoos $(\mathrm{OR}=$ $3.34 ; 95 \% \mathrm{CI}: 1.14-9.70 ; \mathrm{P}=0.02)$, and negatively associated with drug abuse $(\mathrm{OR}=0.28 ; 95 \% \mathrm{CI}: 0.11-0.70 ; \mathrm{P}=0.007)$.

Manuscript accepted for publication December 19, 2013

\footnotetext{
${ }^{a}$ Biomedical Research Laboratory, Faculty of Medicine and Nutrition, Juarez University of Durango State, Avenida Universidad S/N, 34000 Durango, Mexico

${ }^{b}$ Institute for Scientific Research, Juarez University of Durango State, Avenida Universidad S/N, 34000 Durango, Mexico

${ }^{\mathrm{c}}$ Clinica de Medicina Familiar, Instituto de Seguridad y Servicios Sociales de los Trabajadores del Estado, Predio Canoas S/N, 34079 Durango, Mexico

${ }^{\mathrm{d}}$ Corresponding author: Cosme Alvarado-Esquivel, Laboratorio de Investigacion Biomedica, Facultad de Medicina y Nutricion, Avenida Universidad S/N, 34000 Durango, Dgo, Mexico.

Email: alvaradocosme@yahoo.com
}

doi: http://dx.doi.org/10.4021/gr583w
Conclusions: Seroprevalence of $H$. pylori exposure in inmates is higher than those found in non-incarcerated people and other populations in the region. Results indicate that inmates may represent a new risk group for $H$. pylori exposure. Results warrant for further research on the potential role of incarceration and behavioral features of inmates for $H$. pylori infection.

Keywords: Helicobacter pylori; Seroprevalence; Inmates; Epidemiology; Mexico

\section{Introduction}

Infections with the bacterium Helicobacter pylori are common among the world's population [1]. The clinical spectrum of infections with $H$. pylori varies from asymptomatic state to severe gastric disease. Infections with $H$. pylori cause chronic gastritis, peptic ulcer, gastric mucosa-associated lymphoid tissue lymphoma and gastric cancer [1-4]. In addition, H. pylori infections have been linked with extra-gastric diseases including sideropenic anemia, idiopathic thrombocytopenic purpura and other conditions [4-6]. A number of transmission routes for $H$. pylori have been reported including oral-oral or fecal-oral [7], person-to-person [8] and consumption of contaminated water [7,9].

The epidemiology of $H$. pylori infection in inmates has not been studied. Inmates should be considered a group of population with epidemiologic importance for $H$. pylori infection since they have a number of relevant characteristics for acquiring such infection. In Mexico and probably in other countries, inmates live mostly in overcrowding conditions. Overcrowding may facilitate the oral-oral and fecaloral routes of $\mathrm{H}$. pylori infection. In addition, overcrowding and confinement may facilitate the person to person route of infection with $\mathrm{H}$. pylori too. Therefore, this study was aimed to determine the seroprevalence of anti- $H$. pylori antibodies in inmates in Durango City, Mexico. In addition, seroprevalence association with socio-demographic, clinical, incarceration and behavioral characteristics in inmates was examined. 
Table 1. Socio-Demographic and Incarceration Characteristics of Inmates and Seroprevalence of $H$. Pylori Infection

\begin{tabular}{|c|c|c|c|c|}
\hline \multirow{2}{*}{ Characteristic } & \multirow{2}{*}{$\begin{array}{l}\text { No. of subjects } \\
\text { tested }^{\text {a }}\end{array}$} & \multicolumn{2}{|c|}{ Prevalence of $\boldsymbol{H}$. pylori infection } & \multirow{2}{*}{ Pvalue } \\
\hline & & No. & $\%$ & \\
\hline \multicolumn{5}{|l|}{ Gender } \\
\hline Male & 129 & 107 & 82.9 & \multirow[t]{2}{*}{0.8} \\
\hline Female & 39 & 33 & 84.6 & \\
\hline \multicolumn{5}{|l|}{ Age groups (years) } \\
\hline 30 or less & 85 & 69 & 81.2 & \multirow{3}{*}{0.54} \\
\hline $31-50$ & 69 & 58 & 84.1 & \\
\hline$>50$ & 14 & 13 & 92.9 & \\
\hline \multicolumn{5}{|l|}{ Birth place } \\
\hline Durango State & 120 & 100 & 83.3 & \multirow[t]{2}{*}{1} \\
\hline $\begin{array}{l}\text { Other Mexican state or } \\
\text { abroad }\end{array}$ & 48 & 40 & 83.3 & \\
\hline \multicolumn{5}{|l|}{ Residence } \\
\hline Durango State & 135 & 113 & 83.7 & \multirow[t]{2}{*}{0.79} \\
\hline Other Mexican State & 33 & 27 & 81.8 & \\
\hline \multicolumn{5}{|l|}{ Marital status } \\
\hline Single & 44 & 37 & 84.1 & \multirow[t]{5}{*}{0.01} \\
\hline Married & 72 & 58 & 81.0 & \\
\hline Divorced & 4 & 1 & 25.0 & \\
\hline Living together & 41 & 37 & 90.2 & \\
\hline Widowed & 6 & 6 & 100.0 & \\
\hline \multicolumn{5}{|l|}{ Occupation } \\
\hline Laborer $^{b}$ & 153 & 127 & 83.0 & \multirow[t]{2}{*}{0.52} \\
\hline Non-laborer ${ }^{\mathrm{c}}$ & 15 & 13 & 86.7 & \\
\hline \multicolumn{5}{|l|}{ Socio-economic level } \\
\hline Low & 106 & 90 & 84.9 & \multirow[t]{3}{*}{0.33} \\
\hline Medium & 52 & 40 & 76.9 & \\
\hline High & 3 & 3 & 100.0 & \\
\hline \multicolumn{5}{|l|}{ Jail section } \\
\hline A & 24 & 21 & 87.5 & \multirow[t]{5}{*}{0.91} \\
\hline B & 3 & 2 & 66.7 & \\
\hline $\mathrm{C}$ & 38 & 32 & 84.2 & \\
\hline $\mathrm{D}$ & 41 & 34 & 82.9 & \\
\hline E & 62 & 51 & 82.3 & \\
\hline \multicolumn{5}{|l|}{ Number of incarcerations } \\
\hline One & 130 & 108 & 83.1 & \multirow[t]{2}{*}{0.86} \\
\hline Two or more & 38 & 32 & 84.2 & \\
\hline \multicolumn{5}{|l|}{$\begin{array}{l}\text { Duration (years) of current } \\
\text { incarceration }\end{array}$} \\
\hline $0.5-1$ & 47 & 41 & 87.2 & \multirow[t]{5}{*}{0.12} \\
\hline $1.1-2$ & 56 & 51 & 91.1 & \\
\hline $2.1-3$ & 23 & 17 & 73.9 & \\
\hline $3.1-5$ & 26 & 19 & 73.1 & \\
\hline More than 5 & 16 & 12 & 75.0 & \\
\hline
\end{tabular}

aSubjects with available data; 'Laborer: Agriculture, construction worker, business, driver, factory worker, other; 'Non-laborer: student or housekeeping. 
Table 2. Bivariate Analysis of Selected Behavioral Characteristics in Inmates and H. Pylori Seroprevalence

\begin{tabular}{|c|c|c|c|c|}
\hline \multirow{2}{*}{ Characteristic } & \multirow{2}{*}{$\begin{array}{l}\text { Subjects } \\
\text { No. }\end{array}$} & \multicolumn{2}{|c|}{ Prevalence of $\boldsymbol{H}$. pylori infection } & \multirow{2}{*}{$P$ value } \\
\hline & & No. & $\%$ & \\
\hline \multicolumn{5}{|l|}{ National trips } \\
\hline Yes & 80 & 64 & 80.0 & 0.24 \\
\hline No & 83 & 72 & 86.7 & \\
\hline \multicolumn{5}{|l|}{ Traveled abroad } \\
\hline Yes & 61 & 48 & 78.7 & 0.22 \\
\hline No & 107 & 92 & 86.0 & \\
\hline \multicolumn{5}{|l|}{ Drug abuse } \\
\hline Yes & 67 & 51 & 76.1 & 0.04 \\
\hline No & 100 & 88 & 88.0 & \\
\hline \multicolumn{5}{|l|}{ Alcoholism } \\
\hline Yes & 106 & 88 & 83.0 & 0.88 \\
\hline No & 62 & 52 & 83.9 & \\
\hline \multicolumn{5}{|l|}{ Tattoos } \\
\hline Yes & 53 & 47 & 88.7 & 0.20 \\
\hline No & 115 & 93 & 80.9 & \\
\hline \multicolumn{5}{|l|}{ Piercing } \\
\hline Yes & 60 & 49 & 81.7 & 0.66 \\
\hline No & 108 & 91 & 84.3 & \\
\hline
\end{tabular}

a Subjects with available data.

\section{Materials and Methods}

\section{Study design and study populations}

Through a case-control study using serum samples from previous Toxoplasma gondii and viral hepatitis serosurveys [10, 11], 168 inmates (cases) and 168 controls were examined for the presence of anti-H. pylori IgG antibodies. Inclusion criteria for the inmates were: 1) current incarceration in the state correctional in Durango City, Mexico; 2) aged 18 years and older; 3) any gender; 4) incarceration for at least 6 months; and 5) who accepted to participate in the study. Inmates included in the study were $18-73$ (mean $=33.2$ \pm 10.79 ) years old: 129 were males and 39 were females. Controls were subjects without incarceration from the same Durango, City. Controls were matched with cases by age and gender. They were $18-73($ mean $=33.7 \pm 11.60)$ years old:
129 were males and 39 were females. Age was comparable between cases and controls $(\mathrm{P}=0.73)$.

Socio-demographic, clinical, incarceration and behavioral data

A questionnaire was administered to collect socio-demographic, clinical, incarceration and behavioral characteristics of the participants. Socio-demographic items included age, gender, birthplace, residence, marital status, occupation and socioeconomic level. Clinical items included the presence of underlying diseases in general and gastric disease in particular. In women, obstetric history was obtained. Incarceration characteristics assessed included number of incarcerations, jail section and duration of current incarceration. Behavioral items included foreign travel, alcoholism, drug abuse, piercing and tattoos. 


\section{Serologic detection of $\boldsymbol{H}$. pylori antibodies}

A commercially available enzyme-linked immunosorbent assay (ELISA) kit, Anti-H. pylori IgG AccuBind ELISA (Monobind Inc, Lake Forest, California) was used to detect IgG antibodies against $H$. pylori in the serum of the participants. The ELISA used allows qualitative and quantitative analyses of anti-H. pylori IgG antibodies. Anti-H. pylori IgG antibody levels were expressed as Units $(\mathrm{U}) / \mathrm{mL}$, and a value higher than $20 \mathrm{U} / \mathrm{mL}$ was considered a positive result. All tests were performed following the manufacturer's instructions.

\section{Statistical analysis}

Analyses were performed using the Microsoft Excel 2010, Epi Info version 3.5.4 software (Centers for Disease Control and Prevention: http://wwwn.cdc.gov/epiinfo/) and SPSS version 15.0 software (SPSS Inc., Chicago, Illinois). Age between cases and controls was compared by the Student's t test. Pearson's chi-square test was used to determine inmate characteristics associated with $H$. pylori seropositivity. In addition, inmates characteristics with a $P$ value $\leq 0.25$ obtained in the bivariate analysis were entered into a multivariate analysis using a conditional backward stepwise logistic regression analysis. Odds ratios (OR) and 95\% confidence intervals $(\mathrm{CI})$ were calculated, and a $\mathrm{P}$ value $<0.05$ was considered statistically significant.

\section{Ethics statement}

Only archival serum samples and data from previous surveys were examined in the present study. However, in the previous surveys, the purpose and procedures of the studies were explained to all participants, and a written informed consent was obtained from each participant. This study was approved by the Ethical Committee of the Instituto de Seguridad y Servicios Sociales de los Trabajadores del Estado in Durango City.

\section{Results}

Anti-H. pylori IgG antibodies were detected in 140 (83.3\%) of 168 inmates and in 101 (60.1\%) of 168 controls. Seroprevalence of anti- $H$. pylori IgG antibodies was significantly higher in inmates than in controls $(\mathrm{OR}=3.32 ; 95 \%$ CI: 1.93 - 5.71; $\mathrm{P}=0.000002)$. Stratification by gender also showed differences in seroprevalence between inmates and controls. Anti-H. pylori $\mathrm{IgG}$ antibodies were detected in $33(84.6 \%)$ of 39 female inmates and in $22(56.4 \%)$ of 39 female controls. Seroprevalence of anti- $H$. pylori IgG antibodies was significantly higher in female inmates than in female controls (OR $=4.25 ; 95 \%$ CI: $1.30-14.43 ; \mathrm{P}=0.006)$. Anti-H. pylori $\operatorname{IgG}$ antibodies were detected in 107 (82.9\%) of 129 male inmates and in $79(61.2 \%)$ of 129 male controls. Seroprevalence of anti-H. pylori $\operatorname{IgG}$ antibodies was significantly higher in male inmates than in male controls $(\mathrm{OR}=3.08 ; 95 \%$ CI: 1.66 $5.73 ; \mathrm{P}=0.0001)$. Of the $140 \mathrm{H}$. pylori $\mathrm{IgG}$ positive inmates, 90 (64.3\%) had IgG levels higher than $100 \mathrm{U} / \mathrm{mL}, 21(15.0 \%)$ between 51 and $100 \mathrm{U} / \mathrm{mL}$, and 29 (20.7\%) between 21 and $50 \mathrm{U} / \mathrm{mL}$. Anti- $H$. pylori $\mathrm{IgG}$ antibody levels were similar in male and female inmates $(\mathrm{P}=0.54)$.

Of the socio-demographic and incarceration characteristics (Table 1), only two characteristics had $\mathrm{P}$ values $\leq 0.25$ : marital status $(\mathrm{P}=0.01)$ and duration of current incarceration $(\mathrm{P}=0.12)$. Other socio-demographic and incarceration characteristics in inmates including age, gander, birth place, residence, occupation, socioeconomic status, jail section and number of incarcerations had $\mathrm{P}$ values $>0.25$.

The seroprevalence of $H$. pylori infection in healthy inmates $(82.0 \%)$ was comparable with that $(85.5 \%)$ found in ill inmates $(\mathrm{P}=0.57)$. There were 3 inmates suffering from peptic ulcer and all 3 were positive for anti-H. pylori antibodies. In addition, there were 2 inmates suffering from gastritis and one of them was positive for anti-H. pylori antibodies. None of the obstetric characteristics in women including pregnancies, deliveries, cesarean sections and abortions was associated with $H$. pylori seropositivity.

Of the behavioral characteristics of inmates examined (Table 2), the following variables had $P$ values $\leq 0.25$ in the bivariate analysis: national trips $(\mathrm{P}=0.24)$, traveled abroad $(\mathrm{P}=0.22)$, drug abuse $(\mathrm{P}=0.04)$ and having tattoos $(\mathrm{P}=$ 0.20 ). Multivariate analysis of socio-demographic, incarceration and behavioral characteristics of inmates that had $P$ values $\leq 0.25$ in the bivariate analysis revealed that only 2 characteristics were associated with $\mathrm{H}$. pylori seropositivity: having tattoos had a positive association $(\mathrm{OR}=3.34 ; 95 \%$ CI: $1.14-9.70 ; \mathrm{P}=0.02)$, and drug abuse had a negative association $(\mathrm{OR}=0.28 ; 95 \% \mathrm{CI}$ : $0.11-0.70 ; \mathrm{P}=0.007)$.

\section{Discussion}

In the present study, a statistically significant difference in H. pylori seropositivity between inmates and controls was found. Remarkably, inmates had a higher seroprevalence of $H$. pylori exposure than controls. In addition, the seroprevalence found in inmates (83.3\%) represents the highest seroprevalence reported in people in the region so far. In recent studies in ethnic groups in Durango, Mexico, the seroprevalences of $H$. pylori exposure in Mennonites [12] and Tepehuanos [13] were $50.7 \%$ and $66.0 \%$, respectively. The seroprevalence found in inmates is also higher than a $66.7 \%$ seroprevalence found in waste pickers in Durango City [14]. Furthermore, the seroprevalence found in inmates is higher than the mean national seroprevalence $(66 \%)$ reported in Mexico [15]. It is not clear why inmates had a higher serop- 
revalence of $H$. pylori exposure than controls. However, all known routes for $H$. pylori infection including oral-oral or fecal-oral [7], person-to-person [8] and consumption of contaminated water $[7,9]$ might be present in inmates. In contrast, such routes of transmission in non-incarcerated people might be less frequent. Inmates live mostly in overcrowding conditions in Mexico and such factor might account for transmission of $H$. pylori infection by the oral-oral and fecal-oral routes. Crowding has been found associated with $H$. pylori infection [15-17] and is clearly an important factor that could contribute for explaining the high seroprevalence of $H$. pylori in inmates. Of the socio-demographic, incarceration and behavioral characteristics of inmates, multivariate analysis revealed that $H$. pylori seropositivity was positively associated with having tattoos and negatively associated with drug abuse $(\mathrm{OR}=0.28 ; 95 \%$ CI: $0.11-0.70 ; \mathrm{P}=0.007)$. Such associations were unexpected. To the best of our knowledge H. pylori seropositivity has not been associated with having tattoos and drug abuse. It is not clear why inmates with tattoos had a higher seroprevalence of $H$. pylori exposure than those without tattoos. It is uncertain whether $H$. pylori can be transmitted by tattooing. It is possible that inmates with tattoos have had an unknown behavioral risk for $H$. pylori infection. Further studies to confirm or challenge the association of $H$. pylori infection with having tattoos are needed. On the other hand, the negative association of drug abuse with $H$. pylori is intriguing too. We are not aware of previous reports of such association. It is not clear why inmates with drug abuse had a lower seroprevalence of $H$. pylori exposure than inmates without drug abuse. This finding might just indicate that drug abuse did not have any role in H. pylori infection. Nevertheless, it raises the question whether any drug used by inmates might have an adverse effect against $H$. $p y$ lori. It is also possible that inmates without drug abuse have had an unknown behavioral risk factor for $H$. pylori. Further studies to confirm or challenge the negative association of $H$. pylori infection with drug abuse are needed.

The seroprevalence of $H$. pylori exposure in inmates is higher than those found in non-incarcerated people and other reported seroprevalences in the region. Results indicate that inmates represent a new risk group for $H$. pylori exposure. Results warrant for further research on the potential role of incarceration and behavioral features of inmates for $H$. $p y$ lori infection.

\section{Conflict of Interests}

The authors declare that no conflict of interests exists.

\section{References}

1. Sachs G, Scott DR, Wen Y. Gastric infection by Heli- bacter pylori. Curr Gastroenterol Rep. 2011;13(6):540546.

2. Malfertheiner P. The intriguing relationship of Helicobacter pylori infection and acid secretion in peptic ulcer disease and gastric cancer. Dig Dis. 2011;29(5):459464.

3. Zabaleta J. Multifactorial etiology of gastric cancer. Methods Mol Biol. 2012;863:411-435.

4. Selgrad M, Bornschein J, Rokkas T, Malfertheiner P. Helicobacter pylori: gastric cancer and extragastric intestinal malignancies. Helicobacter. 2012;17(Suppl 1):30-35.

5. Banic M, Franceschi F, Babic Z, Gasbarrini A. Extragastric manifestations of Helicobacter pylori infection. Helicobacter. 2012;17(Suppl 1):49-55.

6. Suzuki H, Franceschi F, Nishizawa T, Gasbarrini A. Extragastric manifestations of Helicobacter pylori infection. Helicobacter. 2011;16(Suppl 1):65-69.

7. Goh KL, Chan WK, Shiota S, Yamaoka Y. Epidemiology of Helicobacter pylori infection and public health implications. Helicobacter. 2011;16(Suppl 1):1-9.

8. Ford AC, Axon AT. Epidemiology of Helicobacter pylori infection and public health implications. Helicobacter. 2010;15(Suppl 1):1-6.

9. Fedichkina TP, Solenova LG. [Helicobacter pylori: routes of transmission of infection (a review of literature)]. Gig Sanit. 2011;4:30-34.

10. Alvarado-Esquivel C, Sablon E, Martinez-Garcia S, Estrada-Martinez S. Hepatitis virus and HIV infections in inmates of a state correctional facility in Mexico. Epidemiol Infect. 2005;133(4):679-685.

11. Alvarado-Esquivel C, Estrada-Martinez S, Pizarro-Villalobos H, Arce-Quinones M, Liesenfeld O, Dubey JP. Seroepidemiology of Toxoplasma gondii infection in general population in a northern Mexican city. J Parasitol. 2011;97(1):40-43.

12. Alvarado-Esquivel C. Seroepidemiology of Helicobacter pylori infection in a Mennonite community in Durango State, Mexico. Helicobacter. 2013;18(3):215221.

13. Alvarado-Esquivel C. Seroepidemiology of Helicobacter pylori infection in Tepehuanos aged 15 years and older in Durango, Mexico. J Pathog. 2013;2013:243246.

14. Alvarado-Esquivel C. Helicobacter pylori infection in waste pickers: a case control seroprevalence study. Gastroenterol Res. 2013;6(5):174-179.

15. Torres J, Leal-Herrera Y, Perez-Perez G, Gomez A, Camorlinga-Ponce M, Cedillo-Rivera R, Tapia-Conyer $\mathrm{R}$, et al. A community-based seroepidemiologic study of Helicobacter pylori infection in Mexico. J Infect Dis. 1998;178(4):1089-1094.

16. Porras C, Nodora J, Sexton R, Ferreccio C, Jimenez S, Dominguez RL, Cook P, et al. Epidemiology of Helicobacter pylori infection in six Latin American coun- 
tries (SWOG Trial S0701). Cancer Causes Control. 2013;24(2):209-215.

17. Goodman KJ, O’Rourke K, Day RS, Wang C, Redlinger
T, Campos A, de la Rosa JM. Helicobacter pylori infection in pregnant women from a U.S.-Mexico border population. J Immigr Health. 2003;5(3):99-107. 